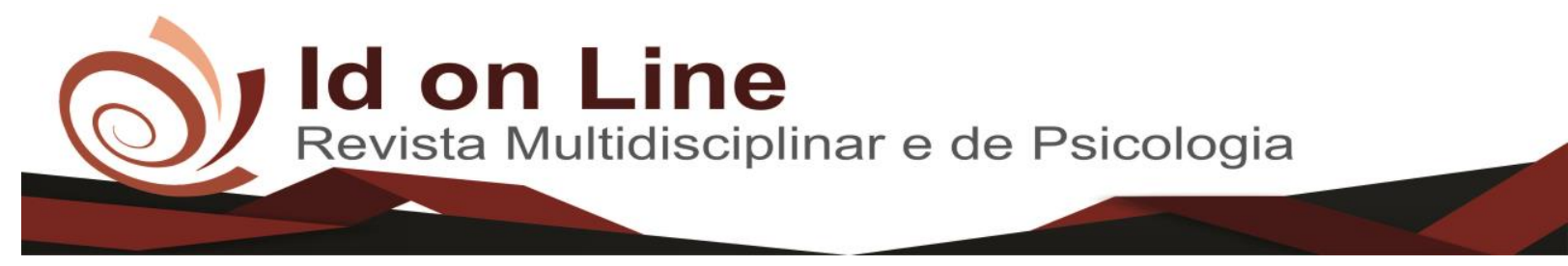

Comment

\title{
A Inclusão Educacional de Alunos com Autismo: Desafios e Possibilidades
}

\author{
Marìlia Marluce da Silva ${ }^{\text {; }}$ Cícera Alves Nunes ${ }^{2}$; Maria do Socorro Cecílio Sobral ${ }^{3}$
}

\begin{abstract}
Resumo: O presente trabalho teve a finalidade de realizar uma discussão sobre a inclusão educacional do aluno com autismo sem preconceito nenhum em sala de aula, onde esta ou qualquer outra deficiência, que os mesmos tenham o direito de inclusão em escolas do ensino regular. O objetivo foi compreender como acontece a inclusão educacional de alunos com deficiência no ensino regular. Diante dos estudos realizados para desenvolvimento deste trabalho de pesquisa científica no que concerne ao conceito ficou evidente que o autismo é um transtorno global do desenvolvimento caracterizado por alterações significativas no desenvolvimento, prejudicando totalmente a capacidade na comunicação, na interação social e no comportamento da criança. A metodologia utilizada foi uma revisão bibliográfica de caráter qualitativo. Ao longo do estudo perceberam-se como resultados: a importância do processo de inclusão no ensino regular, fator defendido pela lei vigente, assim como a mediação do professor neste processo e no desafio de ensinar o aluno autista para o seu desenvolvimento pleno, com suas limitações, mas jamais excluído do processo que a ele é garantido o direito por lei. Ainda nesse contexto percebeuse que o aprendizado é individual ocorre de modo diferente para cada aluno, há necessidade da escola e a família estarem sempre preparadas para que aconteça realmente a inclusão, de mãos dadas buscando a socialização, interação e mediação para uma aprendizagem, onde a escola tem que ser um ambiente acolhedor e de uma educação de qualidade.
\end{abstract}

Palavras - chave:Aprendizagem,Autismo,Inclusão educacional.

\section{Educational Inclusion of Students with Autism: Challenges and Possibilities}

\begin{abstract}
The present work had the purpose of conducting a discussion about the educational inclusion of the student with autism without prejudice in the classroom, where this or any other deficiency that they have the right to inclusion in schools of regular education. The objective was to understand how the educational inclusion of students with disabilities occurs in regular education. Considering the studies carried out to develop this scientific research work regarding the concept, it was evident that autism is a global developmental disorder characterized by significant developmental alterations, totally impairing communication capacity, social interaction and child behavior. The methodology used was a bibliographical review of a qualitative nature. Throughout the study, the following results were observed: the importance of the inclusion process in regular education, a factor defended by current law, as well as teacher mediation in this process and the challenge of teaching autistic students to their full development, with their limitations, butnever excluded from the process that he is guaranteed the right by law. In this context, it was noticed that the individual learning occurs in a different way for each student, there is a need for the school and the family to be always ready for the inclusion to take place, hand in hand seeking socialization, interaction and mediation for learning, where the school has to be a welcoming environment and a quality education.
\end{abstract}

Key words: Educational inclusion. Autism.Learning

\footnotetext{
${ }^{1}$ Faculdade de Ciências Humanas do Sertão Central (FACHUSC). marilliah24@ gmail.com;

${ }^{2}$ Faculdade de Ciências Humanas do Sertão Central (FACHUSC). professoraciceranunes07@ gmail.com;

${ }^{3}$ Faculdade de Ciências Humanas do Sertão Central (FACHUSC). socorrosobral@ bol.com.br.
} 


\section{Introdução}

O termo inclusão tem chamado muito a atenção nos últimos tempos. A inclusão escolar de alunos com autismo tem como propósito inserir todas as crianças e adolescentes no âmbito escolar independentemente do seu grau de desenvolvimento. Foi importante relatar que a educação inclusiva para crianças com autismo deverá ser feita nas escolas regulares. Assim tendo como finalidade inserir a criança sem preconceito nenhum na sala de aula. A Inclusão Educacional de alunos com autismo, foco principal dessa pesquisa, teve como objetivo geral compreender como acontece a inclusão educacional de alunos com deficiência no ensino regular, buscando assim uma melhor solução para essa inclusão. A pesquisa explica-se ainda sobre os seguintes objetivos específicos: compreender como se dá o desenvolvimento cognitivo de alunos autistas; analisar a prática pedagógica dos professores para a inclusão educacional de alunos autistas, analisar os pressupostos teórico-práticos da inclusão do aluno autista, identificar sintomas e características comuns do transtorno autista, compreender a participação da escola e da família no processo de inclusão, e o desenvolvimento do aluno autista.

O mesmo contempla ainda a perspectiva que a avaliação da aprendizagem assume sentidos orientados e cooperativos ressalta que aprender é construir seu próprio conhecimento, e também, que os instrumentos de avaliação são apenas mediadores e com isso afastam-se das características humanas. Avaliar é um ato de responsabilidade e comprometimento ético e moral. Trabalhar com autista requer uma grande responsabilidade não só dos profissionais, mas também da família em si, onde juntas irão desenvolver um papel de suma importância na vida da criança autista, melhorando assim o seu desenvolvimento.

Diante do exposto a minha motivação deu-se por conta de um aluno autista, onde o mesmo tinha um comportamento diferenciado. A criança com autismo se desenvolve de maneira mais lenta se comparada com as que apresentam desenvolvimento típico. Ela é capaz de interagir e participar, mas da forma dela, talvez não como a escola ou a família espera os autistas tem dificuldade de lidar com mudanças, por menores que sejam, por isso é importante manter o seu mundo organizado e dentro da rotina. Através do relato, quais desafios que enfrentam os professores para promover a inclusão de alunos com autismo?

Como resultado dos estudos percebeu-se que o aprendizado é individual, e não ocorre da mesma maneira em duas crianças, tenham elas deficiências ou não. A escola deve estar atenta a esse fato e evitar o autoritarismo, não deve jamais esperar resultados idênticos de indivíduos diferentes. A metodologia é a chave da questão para de fato incluir os alunos com autismo, é 
preciso que esta esteja preparada. O que isso significa? Conhecer cada caso, envolver-se com a questão, mantendo inclusive contato com os pais e com outros profissionais que atendam a criança.

A adaptação do conteúdo e a aplicação de uma metodologia válida, que funcione para aquela determinada criança, são as grandes responsabilidades dos professores que tem na classe um ou mais alunos com autismo ou outra deficiência. Há também a questão da convivência, para os professores, os desafios são melhorar as maneiras de se comunicar e intermediar a interação do aluno com os demais, como também a falta de formações especificas para estes profissionais atuares na sala de aula com o seu aluno autista. Estes são os principais desafios para um docente na sua vida em sala de aula, fazer com quer todos se interajam e que de fato ocorra à inclusão.

\section{A inclusão escolar}

Segundo Sampaio (2009, p.23) "ao longo dos anos 90 e até os dias de hoje, a educação inclusiva vem firmando-se no plano internacional e na legislação brasileira como uma conquista dos direitos humanos". Percebe-se então que todos os alunos tenham os mesmos espaços educativos, uma vez que o sentido é transformar a escola para acolher todos os indivíduos mesmo com suas diferenças e características.

Entretanto, apesar da justiça da proposta de não se excluir uma criança do acesso à educação por sua singular condição física ou mental, o que percebemos é um total despreparo da sociedade em geral e das instâncias educacionais em particular, para empreender a tarefa de transformação que a inclusão exige.

Diante das constantes referências às dificuldades de implantação deum projeto inclusivo nas escolas, acredita-se que seja necessário considerar, não só os entraves político-pedagógicos tão comumente mencionados, mas também as vivências estimulantes e frustrantes surgidas no cotidiano das relações estabelecidas entre os participantes da comunidade escolar.

No entanto, sabemos que a escola já se debate para conviver com a diversidade sociocultural, há de se reconhecer que a deficiência, historicamente segregada, não só da escola, mas de outras formas de convivência social, encarna a diversidade na sua forma mais radical, e por isso mesmo, pode causar as mais diversas resistências para que seja aceita nas salas de aula. Deve-se, portanto, admiti-la para que possa ser trabalhada, a fim de que o professor possa sair 
de uma postura imobilizante diante da deficiência e adotar uma prática pedagógica efetivamente inclusiva.

É importante saber que a escola inclusiva foi oficialmente assumida por diversos outros países, através da ONU/UNESCO, DE 1994. A conferência mundial teve como documento final, relatar sobre a necessidades educativas, ocorrido na Europa propondo implementar nos sistemas educacionais, programas que garantam ao aluno uma educação de qualidade. Vale salientar que o mérito da escola inclusiva de tentar mudar as atitudes de discriminação, criando comunidades mais acolhedoras. Esta proposta vem sendo gradativamente implementada em muitos países como Espanha (COOL, PALACIOS E MARCHESI, 1995), EUA, Canadá, Austrália, Itália, Inglaterra (STAINBACK e STAINBACK, 1999), Chile, Moçambique e Angola (CROCHÍK, 2002)

O reflexo de tal movimento pela inclusão está visivelmente expresso na legislação brasileira, que se posiciona pelo atendimento dos alunos com dificuldades educacionais, preferencialmente em salas comuns da escola, em todos os níveis, etapas e modalidade de educação e ensino (BRASIL, 1999). Apesar de trazer ainda alguma ambiguidade, a nova versão da Lei de Diretrizes e Bases (1996). Nesta linha de estudo comenta Torezan $(2002$, p.37) apresenta pontos que indicam avanços, como o estabelecimento de relações mais estreitas entre ensino regular e especial, a ampliação do poder público, a oferta da Educação Especial durante a educação infantil”.

\section{Sintomas e características comuns do transtorno autista}

O termo autismo origina-se do grego auto que significa "de si mesmo". Foi empregado pela primeira vez pelo psiquiatra suíço Eugen Bleuler, em 1911, que buscava descrever a fuga da realidade e o retraimento interior dos pacientes acometidos de esquizofrenia. (CUNHA, 2012, p.20).

O autismo é um transtorno global do desenvolvimento (TGD), caracterizado por alterações significativas no desenvolvimento, prejudicando totalmente a capacidade na comunicação, na interação social e no comportamento da criança. Essas três alterações que apareceram juntas caracterizaram o autismo, foram chamados por Lorna Winy e Judith Goul, em seus estudos realizados em 1979 de "tríade”. Essa tríade é responsável por um paradigma de comportamento restrito e repetitivo. Através dessa tríade podemos citar: dificuldade de comunicação. Percebe-se que a criança tem uma grande dificuldade na fala, dando uma 
impressão de ser uma criança tímida, usa sempre gestos para sua melhor comunicação e tem dificuldade de interação social. Notou-se que a criança sente dificuldade no ato de interagir com o próximo, sente-se isolada nas brincadeiras por ser muito obsessivo pelos brinquedos de outras crianças. Com relação às dificuldades comportamentais nota-se que o comportamento da criança além de prejudicar no seu desenvolvimento, interfere ainda mais no meio social a qual estão inseridas. Apresenta muitas vezes repetição de movimentos, vivem no mundo imaginário, e expressam comportamentos obsessivos no seu dia a dia.

Vale ressaltar que, algumas crianças tem muita dificuldade na sua aprendizagem, uma vez que a mesma não tem atenção necessária para o seu melhor desenvolvimento. Entende-se que para uma boa aprendizagem, será necessário estimular a comunicação e a interação, pois para uma criança autista a maior dificuldade é a falta de concentração. $\mathrm{O}$ desenvolvimento de aprendizagem do indivíduo autista tende-se a ser de uma forma lenta e repetitiva.

O autismo é definido pela Organização Mundial da Saúde (OMS) como:

Um distúrbio do desenvolvimento, sem cura e severamente incapacitante. Sua incidência é de cinco casos em cada 10.000 nascimentos caso se adote um critério de classificação rigoroso, é três vezes maior, se considerarmos casos correlatados, isto é, que necessitem do mesmo tipo de atendimento. (MANTOAN, 1997, p.13)

No momento o autismo não tem cura, mas tem tratamento; a criança deve ser acompanhada por vários profissionais, a avaliação deverá ser interdisciplinar feita com participação de médicos neurologista, psicólogos, pedagogos, terapeuta ocupacional, fonoaudiólogo, professores a família também precisa ser ouvida para o fechamento da avaliação e diagnóstico. O laudo só poderá ser dado por médico depois da observação e escuta da equipe interdisciplinar.

\section{A participação da escola e da família no processo de inclusão}

Sabe-se que a relação família e escola é fundamental para o desenvolvimento pleno das aprendizagens das crianças em fase aos anos iniciais do Ensino, sobretudo nas escolas regulares, tendo em vista a formação e desempenho nas habilidades para uma aprendizagem significativa. E no que se refere às crianças com deficiência elas devem acontecer com maior veemência e interação, para efeitos de suas fragilidades. Em 1994 surge a Declaração de Salamanca, promovida pelo governo da Espanha e pela Unesco, realizada na Conferência Mundial sobre as Necessidades Especiais, onde reconheceram a obrigação de o ensino chegar a todas as crianças, 
jovens e adultos com necessidades especiais, em ensino regular, de acordo com Sanchez essa declaração proclama que,

[...]Todas as crianças têm direito à educação e deve-se dar a elas a oportunidade de alcançar e manter um nível aceitável de conhecimentos; Cada criança tem características, interesses, capacidades e necessidades de aprendizagem que lhe são próprias; Os sistemas de ensino devem ser organizados e os programas aplicados de modo que tenham em conta todas as diferentes características e necessidades; As pessoas com necessidades educacionais especiais devem ter acesso às escolas comuns; e As escolas comuns devem representar um meio mais eficaz para combater as atitudes discriminatórias, criar comunidades acolhedoras, construir uma sociedade integradora e alcançar a educação para todos.(SANCHEZ,2005,p.9)

A escola tem um papel fundamental no processo da criança autista; onde irá contribuir com todos seus recursos para melhoria no desenvolvimento do autista. A família por ser mais experiente com a criança busca dialogar com a equipe gestora explicitando assim todo o comportamento do mesmo durante o seu dia a dia. Unidas à escola com a família é a medida mais importante para melhoria de vida da criança autista. Pois essa inclusão resultara que a criança vai sentir-se mais confiante durante o seu desenvolvimento dentro da escola e na sociedade.

A maior dificuldade das famílias muitas vezes é isolar a criança, tomando uma atitude de deixá-la dentro de casa e não levar para a escola, atrapalhando assim o seu desenvolvimento escolar. Isso ocorre porque a família tem vergonha da criança por ela ser autista; a família ao invés de isolar deverá procurar ajuda para fazer com que essa criança se desenvolva cognitivamente e tenha um futuro melhor.

\section{O papel do professor para a inclusão educacional dos alunos autistas}

A luta pela implementação da inclusão iniciou-se na década de 1990. Esta por sua vez se destina a alunos pertencentes a minorias sociais que, por diversos motivos, não estavam, anteriormente, presentes nas escolas e salas do ensino regular. Nesta mesma linha de processar a inclusão de alunos com deficiência engloba-se o professor, pois este é o que passa mais tempo buscando caminhos para adequar o ensino aprendizagem para seus alunos. A formação diferencial é muito complexa, sobretudo no ensino regular, onde há tanta carência de subsídios para o trabalho pedagógico. O professor tem a função de mediador do conhecimento, ele é quem ajuda o aluno deficiente ou não tanto no seu processo educacional quanto no processo de interação, levando-o a acreditar no seu potencial. Com o processo de inclusão os alunos 
aprendem a conviver com a diferença na sala de aula e tendem a se tornar cidadãos solidários e responsáveis pelo próximo. Nesse sentido, Santana (2005) apud PRATES (2011) contribui dizendo sobre a preparação dos profissionais da educação:

\begin{abstract}
[...] profissionais educadores para o trabalho de alunos com autismo é de suma importância, pois o educador é um dos agentes responsáveis não somente por transmitir conteúdos pedagógicos, como também transmitir valores e normais sociais que possam inserir a criança na esfera simbólica do discurso social. Sendo assim, o trabalho com educadores deverá englobar, de forma permanente, programas de capacitação, supervisão e avaliação (SANT'ANA, 2005apud PRATES 2011, p. 05).
\end{abstract}

Para uma aprendizagem significativa de uma criança autista, a melhor maneira de trabalho é de forma que incentive o aluno a realizar as atividades, de acordo com sua etapa de desenvolvimento, ou seja, deixar o aluno sempre livre para se interagir com os demais na escola, trocando informações do seu jeito de se comunicar.

O professor precisa estar sempre atento ao aluno autista, notando-se se está desenvolvendo sua aprendizagem corretamente. Assim para melhor desenvolvimento das crianças é fundamental ter um professor auxiliar, onde irá dar suporte ao professor, trabalhando assim de forma diferenciada com o aluno autista, levando a desenvolver atividades para uma melhor aprendizagem. Quem nós diz isso é Vygotsky (1978 apud Santos 2013) quando afirma que:

\footnotetext{
O professor deve ter consciência de sua importância como mediador e compreender que cada criança dentro de sala de aula se desenvolve, amadurece e aprende de forma particular, ou seja, atinge expectativas de aprendizagens únicas e que a todo tempo deve ser valorizada e estimulada a atingir níveis cada vez mais elevados (VYGOTSKY, 1978 apud SANTOS, 2013, p.13)
}

Na maioria das vezes apenas os professores não são suficientes para o desenvolvimento do aluno, é necessário trabalhar em conjunto com a equipe pedagógica para que essa criança se sinta incluída no seu meio social escolar, e também tenha atendimento especializado com fonoaudiólogo, psicólogo, e terapeuta ocupacional para um melhor desenvolvimento.

\title{
Desenvolvimento do aluno autista
}

Para Camargo (2002) existe uma versão que resulta na presença de sintomas acerca da interação social, linguagens e comportamentos imaginativos. Acredita-se que a convivência de um aluno autista ou qualquer outro distúrbio possa dar-lhe oportunidade de se socializar com 
outros indivíduos na escola. Portanto para se trabalhar com um autista deve ter um diagnóstico, para só então desenvolver um trabalho de qualidade para ser desenvolvido com essa criança, respeitando assim seu limite de aprendizagem. Na escola ou em qualquer outro local o autista tem a dificuldade de utilizar o desenvolvimento da linguagem. Criança com autismo aparenta muitas vezes ser preguiçosa, mas não é, o atraso na sua linguagem faz com que a mesma tenha uma grande dificuldade no ato de falar; por este motivo a melhor forma pedagógica para trabalhar o desenvolvimento do autista são jogos, brincadeiras e etc.; trabalhando assim o seu desenvolvimento cognitivo.

\footnotetext{
Para Piaget o desenvolvimento cognitivo è interpretado a partir da experiência com meio físico, e o processo de desenvolvimento intelectual pelo Mecanismo de equilibrarão das ações sobre o mundo. E em Vygotsky, a interação social e o instrumento linguístico são decisivos para compreender o desenvolvimento cognitivo. (CAMARGO apud PIAGET, 2002, p.46)
}

De acordo com Piaget (2002) para melhor desenvolvimento do autista, a primeira área a ser estimulada deve ser o seu cognitivo e a interação; ter contato com os materiais necessários trará para o autista uma forma de aprendizagem mais significativa, mas não é só pelo contato com os objetos que é adquirido o seu conhecimento e sim por meio da comunicação com o próximo, levando o aluno a aprender a aprender por meio da interação com o mundo ao seu redor.

A comunicação do outro com o autista leva o indivíduo a querer participar do assunto mesmo sendo usado o seu meio de desenvolvimento de linguagem. Pereira (2012) nos diz que: "No caso especifico da linguagem, "os sons só se tomam um tipo de linguagem para as crianças quando elas compreendem que as emissões sonoras realizadas pelo adulto carregam uma intenção de prestar atenção a algo".( PEREIRA, 2012, p.07 ).

No entanto o profissional que for trabalhar atividades com a criança autista, deve observar, quais materiais despertam interesse pela criança, perceber quais as brincadeiras favoritas e etc. e dentro desses interesses elaborar atividades que estimule o seu desenvolvimento. Antes de mais nada o autista precisa de muita atenção e precisa ser incluído no meio social, deve ser estimulado e sempre oferecer atividade significativas para favorecer seu processo de aprendizagem, contribuindo desta forma para seu desenvolvimento intelectual.

Sabe-se que a aprendizagem do autista é um processo lento e de muita paciência, pois o seu aprendizado é por meio de repetição, mas o mais importante que deve ser ressaltado e o resultado alcançado pela criança, mesmo com dificuldades tendem a querer aprender, a participar quando o assunto chama sua atenção. 


\section{Metodologia}

O presente artigo apresenta-se numa abordagem de caráter qualitativo, exploratório a partir de estudos bibliográficos e de campo, mediante estudo de caso por conta da importância da temática. A pesquisa aconteceu de forma concisa e objetiva, com reuniões aos sujeitos, no caso professores de uma escola da rede pública de ensino do município de Salgueiro- PE, sob a forma de questionário, onde as professora A,B,C,D, e E apresentaram suas ânsias sobre os desafios com alunos autistas.

\section{Resultados e Discussão}

Em analise a entender os desafios enfrentados pelos professores no sentido de promover a inclusão de alunos com autismo no ensino regular em entrevista, a professora A - da escola doutor Severino Alves de Sá do município de Salgueiro, afirma ter um aluno com autismo, e uma das dificuldades encontradas neste aluno é o acompanhamento diversificado, onde procura medir seu grau de conhecimento aos conteúdos trabalhados. Outro fator é realmente saber se o aluno realmente absorveu o que foi explicado.

A referida professora ainda diz que procura estar sempre acompanhando os assuntos atuais sobre autismo, também sobre outras deficiências. Todavia, a maneira que trabalha para englobar o aluno (a) é manter ele dentro de todas as atividades realizadas dentro e fora da sala de aula. Sendo comprometida com sua ação pedagógica a referida professora ressalta que seu aluno é alegre e interage sempre com os outros alunos da sala, quando o momento envolve barulho, algumas vezes ele se isola, pois o mesmo não gosta de barulho. E ainda que a escola sempre esta disposta a ajudar sempre que necessário, disponibilizando todos os recursos que tem. No entanto, sente existir por parte dos pais uma ausência grande na participação dos mesmos na vida educacional do aluno. Com relação ao aluno, o mesmo vem avançando a cada dia, na sua aprendizagem, também no seu desenvolvimento social o mesmo tem dificuldade de se relacionar com as pessoas.

Ao dialogar com a professora B- a mesma diz que considera como maior dificuldade a ausência de formações especificas para atender ao público autista. Sabemos das competências que um aluno precisa deter em um determinado ano, mas como fazê-lo pedagogicamente e especialmente para um aluno autista é o mais me desafia e ainda que busca principalmente através da internet, meios de estudos e aprimoramento que norteie um melhor entendimento 
para essa vivência, além da praticidade em acessá-los a qualquer momento. A professora também destacou o respeito as suas especificidades, estabelecendo regras e limites que devem ser respeitados por todos. Afirma que segue uma rotina diária para a vivência das atividades em sala. Também que busca incentivá-lo nas interações orais, solicitando sua participação nos experimentos, bem como na resolução das atividades. Sempre que possível utilizo material concreto ou visual para dinamizar a aula e proporcionar formas variadas de aprendizagens.

As dificuldades maiores segundo a professora para com este aluno dão-se no campo da leitura e durante as tarefas em que o mesmo precisa escrever ou transcrever para o caderno. Socialmente falando o mesmo relaciona-se com alguns alunos o que deixa claras as suas preferências na convivência com os outros. Porém durante as recreações diverte-se normalmente com os colegas. Sobre a escola, a mesma libera recurso suficientes, afirma a professora B, especificamente para as crianças com autismo, e ainda que é preciso ser repensados durante a sua aquisição. Com relação à família diz que a participação é muito pouco, embora no caso do aluno com autismo sua família seja bem presente.

No entanto, no que se refere à aprendizagem do aluno tem evoluído de forma significativa e que o mesmo interage com mais independência e resolve questões de matemática com raciocínio muito rápido. Já no desempenho social ele tem melhorado em relação à interação com outros colegas que não são próximos na hora do recreio.

A minha curiosidade foi mais além e em dialogo a professora C- do $4^{\circ}$ ano, a mesma ressalta que o seu aluno com autismo tem uma falta de atenção e concentração muito grande, o aluno não socializa e é um aluno não verbal. No entanto, a mesma incansavelmente realiza pesquisas na internet e revistas para aprimorar seu trabalho didático. Comenta ainda que o seu aluno apresenta grande dificuldade de socialização é um aluno não verbal, interage através de algumas brincadeiras e vídeos. E acrescenta dizendo que um dos maiores desafios é a falta de concentração e a questão da fala, se relaciona com outros alunos sim mais, apenas com aqueles que ele tem afinidade, se isola bastante não consegue compartilhar, muitas vezes ou ate mesmo na maioria das vezes não que brincar com ninguém.

Uma outra dificuldade acrescenta é que a escola tem pouco material e recursos. Mas com relação a relação família e escola sobre o seu aluno é ótima família, mas infelizmente não inclui ele nos projetos, sala de AEE e não contribui muito na questão escolar. Porém, o aluno quando chegou não se relacionava com os outros nem tinha desenvolvimento de fala, hoje já desenvolve algumas palavrinhas, já tem um bom relacionamento com os colegas, realiza atividades de pintura, cobrir, ligar apresenta uma dificuldade quando realiza as atividades por conta da falta de concentração. 
A professora D- com um aluno autista no $2^{\circ}$ ano destaca que como professora ver como dificuldade maior a inclusão do autista nas atividades diária, pois nós professores não possuímos formação o suficiente para lidar com essa deficiência, mesmo buscando conhecer através de pesquisa não acho que seja suficiente. Todavia, busca através da internet compreender um pouco desse mundo a qual vive uma criança autista, mas não considero como o bastante para lidar e faze a inclusão necessária em sala de aula. Um pouco angustiada a mesma desabafa afirmando que como professora é muito complicado, que o fato de ter uma turma numerosa fica difícil pensar o aluno em forma unitária, neste caso acabamos contando com a ajuda de um cuidador, na qual busca maneiras de incluir o aluno ou adaptá-lo ao meio e as atividades propostas.

A professora E- por sua vez comenta que sobre a aluna autista que estuda na sala em que leciona, percebe que ela tem uma boa interação com os colegas, como também com a mesma, desenvolve bem suas tarefas, mas ainda percebeu uma certa dificuldade em dividir atenção com os colegas. A professora E- acrescenta que para ela a maior dificuldade é mesmo a inclusão nas atividades propostas no grupo. No entanto, a escola tem um ótimo acervo para desenvolver o ensino- aprendizagem dos alunos com deficiências.

Que a família ainda não é presente como deveria. Mas, que no caso da aluna em questão posso dizer que os vi duas ou foi três vezes durante o ano letivo, mas acredita que seria importante a família se incluir nesse processo de inclusão. Agora com relação ao desempenho e aprendizagem do seu aluno foi possível perceber tanto a questão da aprendizagem como o meio social na qual ela ocupa, melhorou também sua autonomia, pois no inicio nem sua própria mochila carregava, e hoje já reconhece letras, silabas e pequenas palavras simples, como também interage com os colegas e carrega seu próprio material, neste caso fica claro que com a mediação adequada a criança se desenvolve dentro do seu tempo e limites.

\section{Considerações Finais}

O referido artigo mostrou que a Inclusão Educacional de Alunos com Autismo é um processo contínuo onde busca-se crescer com o educando na perspectiva de uma construção inovadora em seus diferentes aspectos. Para a realização deste artigo foi necessário além dos conhecimentos empíricos, um aprofundamento em leitura sobre o foco em estudo, inclusão do aluno autista. 
Foi possível assim compreender, conhecer e entender um pouco sobre o autismo e ao longo do estudo ter embasamento teórico para os resultados e discussão apresentados destacando que o educador tem que ser paciente, participativo e ativo, e a partir de suas várias indagações, acompanhamento e estudo, consequentemente, poderá mudar e trazer o que é de melhor para o educando no processo de aprendizagem.

A Inclusão Educacional consiste na escola cumprir sua função social, transformadora, favorecendo a aprendizagem do aluno autista, tendo em vista o compromisso de inseri-lo numa sociedade mais justa e solidária, para sua efetivação de sua missão maior que é preciso formar alunos críticos e responsáveis.

As pesquisas realizadas foram de suma importância para vida acadêmica, pois serviram no despertar cada vez maior do interesse pelo tema abordado e assim aprimorar o conhecimento.

\section{Referências}

CAMARGOS Jr, Walter et.al. Autismo Infantil - Sinais Sintomas. In: Transtornos Invasivos do Desenvolvimento. Brasília: Corde, 2002.

CARVALHO, R.E. Educação Inclusiva: com os pingos nos “is". $9^{a}$ ed. Porto Alegre: Mediação de 2013.

CUNHA, Eugênio, Autismo e Inclusão. Psicopedagogia e práticas educativas na escola e na família. 3 ed. Rio de Janeiro. Wak editora, 2012.

BRASIL, (1994). Lei de Diretrizes e Bases da Educação - 9394/96. Brasília: MEC, 1996. Disponível em: < http://www.planalto.gov.br> Acesso em 28/outubro/2018

MANTOAN, M. T. E. A integração de pessoas com deficiência: contribuições para uma reflexão sobre o tema. São Paulo: SENAC, 1997.

PEREIRA, Cíntia Bonfante. Linguagem, Funções Executivas e Teoria da Linguagem no Autismo sem déficit intelectual: estudo de caso. Porto Alegre, 2012.

PRATES, Jacqueline; LUDKE, Rocha. Autismo e inclusão na educação infantil: um estudo sobre as crenças dos educadores. Porto Alegre, 2011.

SÁNCHEZ, Pilar Arnaiz. A Educação Inclusiva: um meio de construir escolas para todos no século XXI. In: Inclusão - Revista da Educação Especial - Out/2005. Disponível em: https: Acesso em Outubro de 2018.

SAMPAIO, Cristiane T.; SAMPAIO, Sônia Maria R. Educação inclusiva: o professor mediando para a vida - Sciello Livros. Disponível em: 〈http://books.scielo.org >.Acesso em 28/outubro/2018 
SANTOS, Neide Pereira. O desenvolvimento intelectual da criança com autismo e o método TEACCH. 2013.

TOREZAN, A. M. (2002). Psicologia escolar e a nova conjuntura educacional brasileira.In R. S. L. Guzzo (Org.), Psicologia escolar: LDB e educação hoje(pp. 35- 47). Campinas, SP: Alínea.

UNESCO (1994). Declaração de Salamanca. Disponível em: 〈http://unesdoc.unesco.org >. Acesso em 28/outubro/2018.

\section{Como citar este artigo (Formato ABNT):}

SILVA, Marìlia Marluce da; NUNES, Cícera Alves; SOBRAL, Maria do Socorro Cecílio. A Inclusão Educacional de Alunos com Autismo: Desafios e Possibilidades. Id on Line Rev.Mult. Psic., 2019, vol.13, n.43, p. 151-163. ISSN: 1981-1179.

Recebido: 13/11/2018;

Aceito: 19/11/2018 